\title{
HISTORY OF INTRAVENOUS ANASTHESIA WITH SIX YEARS' EXPERIENCE IN THE USE OF PENTOTHAL SODIUM.
}

\author{
By RONALD JARMAN, D.S.C., M.R.C.S., D.A. \\ (Senior Anasthetist Princess Beatrice Hospital: Anasthetist Royal Cancer \\ Hospital and E.M.S.)
}

In the year I665 Sigismund Elsholtz first attempted intravenous anæsthesia by injecting a solution of opiate to obtain insensibility. It was not until 1872 , that Ore, Myer and Witzel experimented with chloral hydrate on animals, but this method was not continued. The real work on intravenous anæsthesia started about 1905 when Fedorow, St. Petersburg, reported his results on 530 cases in which he used 0.75 per cent. of Hedonal $\left(\mathrm{CH}_{3} \mathrm{CH}_{2} \mathrm{CH}_{2} \mathrm{CO}\left(\mathrm{CH}_{3}\right) \mathrm{OCH} \mathrm{NH} \mathrm{NH}_{2}\right)$ in a normal saline solution and claimed that he had no fatalities.

Burkhart, after many experiments on dogs, published the results on his first 46 cases of general anæsthesia using ether and chloroform. He injected a solution of 5 per cent. to 7 per cent. warmed to $28^{\circ} \mathrm{C}$. through a cannula into the vein in the arm and found that very variable quantities were required, even up to several litres.

Some of the patients showed syncope, cyanosis and pulmonary œdema. The difficulties of its administration were so great that Isopral $\left(\mathrm{CCL}_{3} \mathrm{CH}(\mathrm{OH}) \mathrm{CH}_{3}\right)$ was used by his successors. Burkhart whilst trying out a solution of a mixture of ether and isopral reported excellent results in seventy cases.

It was during this time that Bier studied regional intravenous anæsthesia of the limbs. A variable amount of 0.5 per cent. novocaine was injected into the veins near the site of the operation. The blood supply at each end of the limb was occluded to keep the novocaine in the veins. In five to ten minutes anæsthesia was complete. From 25 to 200 c.c. of novocaine without adrenalin were required, according to the size of the limb. The method is more successful for operations on the arm, particularly the forearm.

Here is a brief description of the technique used by Gwathmey of America, when he injected 5 per cent. to 7.5 per cent. solution of ether in Ringer's solution.

Thirty minutes before the operation a hypodermic injection of morphine sulphate grs. I $/ 6$ th, atropine sulphate grs. I/Iooth, scopolamine grs. I/Iooth was given. The solution of ether with filtered sterile Ringer's solution at a temperature of $85^{\circ} \mathrm{F}$. was thoroughly mixed in a reservoir placed 8 feet above the floor. A superficial vein which was away from the operator had to be used, and if the elbow was selected, a padded splint was passed beneath the patient and the wrist was bound to it. The skin over the chosen vein was sterilised and a small incision was made and the vein lifted out. The vein was then cut and the cannula inserted and tied in place. The fluid was allowed to flow through an indicator containing a pipette, down through rubber tubing into a blunt cannula until there were the usual signs of anæsthesia. When the desired degree of narcosis was obtained, the flow was reduced by means of the control cock below the indicator, but it had to be continuous. It was necessary to take great care to maintain an unobstructed airway. The dressings were applied before the flow was actually stopped, as the return to consciousness often came very quickly. About I,0oo c.c. of the solution per hour were used, and at the end of the operation the cannula was withdrawn and the wound closed. Very little solution was necessary to maintain the 
anæsthetic tension, once the right level of narcosis had been reached. Anæsthesia was very rapid as the agent was introduced directly into the blood, and the degree of narcosis could be maintained exactly.

In I9I4 experiments on animals were being carried out with hedonal and ether (introduced in I9Io by Siderenko of Cronstadt) and isopral and ether and paraldehyde elsewhere and these drugs were tried in combination with Ringer's solution. Care was taken in the analysis of the blood, urine and fæces, but owing to the uncertainty of the various agents used, this form of narcosis did not become popular.

It was not until I920, after the Great War, that Dutrech tried ether serum and combined it with isopral, as recommended by Burkhart and Hummell. In Mexico they went as far as to inject pure ethyl alcohol, but with mixed success, and an extended trial of the method in France gave bad results.

In I92I, the real period of advance in intravenous anæsthesia began when Daniel and Gabriel Bardet published a paper on their results using somnifaine. About the same time, soneryl $\left(\mathrm{C}_{4} \mathrm{H}_{9} . \mathrm{C}_{2} \mathrm{H}_{5}, \mathrm{C}\right.$.CONH.CONH.CO. $)$ was being used by Tiffineau and de Carnot. It was Fredet and Perlis who realised that somnifaine alone was not sufficient but found that in combination with a subcutaneous injection of morphine grs. I $/ 6$ th and scopolamine grs. I/Iooth, the anæsthesia was more profound and minor operations could be attempted. The one severe drawback to these two drugs was that the patient had a very deep and prolonged sleep, and on waking complained of severe headache and drowsiness.

From that time various chemical firms were experimenting with these barbiturates ; for example, pernocton and amytal. Then came from America a full report by Zerfas, McCullum, Scholne, Swanson, Scott and Clowes. This included two years' experimental studies on animals and their first attempts at anæsthesia on the human being by the barbiturate.

Sodium amytal $\left.\left(\mathrm{CH}_{3}\right)_{2} \mathrm{CH} .\left(\mathrm{CH}_{2}\right)_{2} \cdot \mathrm{C}_{2} \mathrm{H}_{3} \cdot \mathrm{C} . \mathrm{CO} \cdot \mathrm{N} . \mathrm{Na} \cdot \mathrm{CONH} . \mathrm{CO}\right)$ and pentobarbital sodium (nembutal) $\left(\mathrm{CH}_{3} \cdot \mathrm{CH}_{2} \cdot \mathrm{CH}_{2} \cdot \mathrm{CH} \cdot \mathrm{CH}_{3} \cdot \mathrm{C} \cdot\left(\mathrm{C}_{2} \mathrm{H}_{5}\right) \cdot \mathrm{CO}\right.$.N.Na.CO.NH.CO.) were the first barbiturates to be used intravenously in a large number of cases. Owing to the long post-operative sleep and restlessness, they have been largely abandoned, but are still used for convulsions and maniacal patients. It was shown in later reports that administration by the mouth achieved better results.

In I929, Kirschner injected a 3 per cent. solution of avertin $\left(\mathrm{CBr}_{3} \mathrm{CH}_{2} \mathrm{OH}\right)$ in physiological serum giving I c.c. per kilo of body weight and 60 to 8 o c.c. in 45 seconds. The patient went to sleep in about one minute, and woke up five to ten minutes later, unless the narcosis was prolonged by some other form of anæsthesia.

Soneryl returned to popularity in I932. In the same year, with the introduction of sodium evipan (CO.Na.CO.N $\left.\left(\mathrm{CH}_{3}\right) \mathrm{CO} . \mathrm{C}-\left(\mathrm{CH}_{3}\right) \mathrm{C}_{6} \mathrm{H}_{9}\right)$ all these other drugs fell into disrepute. Evipan was discovered by Kropp and Taub, chemists, and used first intravenously on man by Ernst Reinhoff. The patient went to sleep in a few seconds and after a very short time, provided only a small dose of the drug was used, woke up just as quickly.

This drug produced suitable anæsthesia for minor operations. Other users tried it out in conjunction with nitrous oxide, oxygen and with open ether and found it to be a great success. This naturally became the intravenous anæsthetic of choice.

Soon after, in conjunction with Abel (I933), the first paper was published on evipan. At the same time that this paper came out, the Anæsthetic Research Council in this 
country furnished a brief report in the medical journals. Other reports followed, and during I935 I was invited over to the United States to demonstrate the use of evipan and also to show a film illustrating my technique. I learned that another salt or salts, which, according to research workers, was in advance of the German drug, was being produced there. Through the kindness of Lundy (I935) who was doing the original work at the Mayo clinic, I was given facilities to do the early work at my various hospitals in London.

As Magill had introduced nembutal four or five years previously, I approached him to do this work in conjunction with Lundy, but he advised me to proceed as I had done with evipan. It was entirely due to the co-operation of the surgeons with whom I worked that the success of both these drugs was assured.

Pentothal (Jarman and Abel, I936) was released in this country in I936.

Originally two drugs had been produced by research workers in America. They were known there as barbiturate "A" and barbiturate " $\mathrm{B}$," but to avoid confusion they were given numbers and "A" was 8064 and "B" 8076 . Equal samples of these two drugs, which were very closely allied, were sent to Lundy and myself. In the early days there was a considerable difficulty in keeping the drugs stable ; no sterile water was supplied with them, and this was thought to be the fault. With the co-operation of the chemists, this was overcome, and finally Lundy decided that the drug " $\mathrm{A}$ " or 8064 was the one of choice and it became known as :-

PENTOTHAL SODIUM ( $\left.\mathrm{CH}_{3} \mathrm{CH}_{2} \mathrm{CH}_{2} \mathrm{CH} \mathrm{CH} \mathrm{CH}_{3} \mathrm{C}\left(\mathrm{C}_{2} \mathrm{H}_{5}\right) \mathrm{CO} \mathrm{N} \mathrm{Na} \mathrm{CO} \mathrm{NH} \mathrm{CS}\right)$.

Formula. Sodium Ethyl (I - Methyl Butyl) Thio Barbituric Acid.

Description. This is a lemon coloured powder, bitter in taste, and smelling slightly of sulphur. It is rapidly soluble in water, and strongly alkaline. The $\mathrm{pH}$ of a Io per cent. solution being Io.6. The rapid dissociation of pentothal in the blood stream is entirely due to the sulphur atom.

Equipment. A Vann's syringe (Io c.c.) with an eccentric nozzle and needle size I4 with a short bevel should be used in this form of anæsthesia. Only intermittent doses are given with this syringe. For continuous intravenous anæsthesia, the apparatus Abel and I designed is suggested. This is extremely compact, can be carried easily and may be used for other purposes. The apparatus consists of a Io c.c. syringe, with a three-way nozzle which is fixed to the forearm with elastic bracelets. With the control in the central position, the barrel of the syringe communicates directly via the needle to the vein. When the control is turned to the left, one lateral feed communicates directly with the needle, and this position is used for continuous saline-glucose infusion. When the control is turned to the right, the other lateral feed communicates with the flask containing pentothal, and the syringe can thus be loaded with a further dose of anæsthetic, which may then be injected through the needle by turning the control to the mid-position.

In serious cases a patient can have blood transfusion through the operation with pauses for anæsthetic administration. Similarly, for any emergency, the syringe can be used for giving stimulants, such as coramine or alpha-lobeline; and here an advantage of the apparatus is that only the smallest amount necessary of the drug need be given, since it is accurately measured and reaches the vein direct. We have found the administration of continuous saline-glucose infusion during operation of the utmost importance in some of the "poor risk" cases. Dehydration is combated and shock is largely abolished. 
Other forms of continuous intravenous anæsthesia technique will be described later. Quayle (I940) has produced a very excellent type of apparatus.

Type of Patient. From the point of view of anæsthesia patients may be classed as placid and resistant types of out-patients and in-patients.

The placid type will take any form of anæsthetic, not necessarily intravenous, equally well and the amount of the drug used varies slightly; but with the resistant type the dosage varies considerably so that no definite amount can be laid down as a guide to future anæsthetists. No two anæsthetics are ever the same.

Out-patients need never have any form of premedication. Either $\frac{1}{2} \mathrm{grm}$, or I grm. of penthothal may be administered in the surgery or out-patients theatre and minor operations, such as removal of nails, opening of abscesses, setting of fractures, extraction of teeth, cystoscopies, can be performed, and, after allowing the patient to recover in one or two hours and in some cases even less, he may go home.

The in-patient is admitted into hospital or nursing home, or in a private house, and has drugs the night before such as medinal, grs. Io, aspirin grs. Io (average adult), to ensure a good night's rest. Then one hour before the operation he is given an ampoule of omnopon grs. $\frac{1}{3} \mathrm{rd}$, scopolamine grs. I/r5oth. The room is darkened and the patient is left alone. In a general ward a screen is put in front of the bed and the eyes lightly bandaged. Then for the comfort of the patient $\frac{1}{2} \mathrm{grm}$. of pentothal is dissolved in Io c.c. of sterile distilled water, and is injected into a vein whilst he is in bed, making sure that his airway is kept clear, by taking the precaution of asking him to bite on a dental prop. He falls asleep and is taken to the theatre and placed on the operating table, where he can be given more pentothal or another anæsthetic.

The Condition of the Patient. The usual modern methods of investigation and preparation of all patients is carried out before the operation in addition to a general clinical examination and a blood and urine analysis. Special attention is paid to the blood pressure; no enema, purging or other form of dehydration is permitted for at least 48 hours before a major operation. The patient is supplied with plenty of fluids and glucose and everything is done to ensure that his general condition is as good as possible.

Contra-Indications. Liver : Pentothal is metabolised in the liver very rapidly and any gross hepatic disease, or the presence of jaundice, should be definite contra-indication.

Low blood pressure: Extreme care should be taken with any patient who shows general feebleness and low blood pressure as this drug causes a slight, though temporary fall in blood pressure.

Posture: The upright position, except, perhaps, in young healthy subjects, is a contra-indication but under certain circumstances this can be overlooked, as, for example, when giving a spinal anæsthetic (Etherington Wilson's technique) when the patient is under the influence of this drug. For general routine work it is thought advisable that the recumbent posture should be adopted and even for dental work the patient should be put in an inclined plane.

Space: Lack of available space applies only to institutions where large numbers of patients are to be dealt with and where enough room is not available to allow all of them to recover sufficiently to be able to go home.

OTHER BARBITURATES.

It was felt at first that whilst this drug was being established users should be advised not to give other barbiturates previous to the injection of pentothal. This still holds good where the patient has had a long course of barbiturates, especially in the type, 
chiefly women, who complain of not being able to sleep well and resort to such drugs as allonal, medinal and soneryl. It is an accepted practice to-day that nembutal may be given the night before and also one hour before the operation. The suggested dose for an adult is nembutal grs. $\mathrm{I} \frac{1}{2}$, last thing at night and nembutal grs. 3 sixty minutes before the operation. This can be followed with atropin grs. I/rooth so as to dry up the respiratory tract.

Where it is known that the patient has resorted to barbiturates as a means of obtaining sleep over a period of time, considerable care must be taken if an intravenous barbiturate is being used, because the depression of the respiratory centre in these cases is sometimes severe and unpleasant anxiety is experienced.

\section{TECHNIQUE AND ADMINISTRATION.}

Before going into the detail of technique and administration, it is suggested that future users should be trained in intravenous therapy. It is essential that the anæsthetist should have a steady hand, a knowledge of veins and how to combat failures and minor accidents. The number of unsuccessful attempts produced by would-be intravenous therapists are entirely due to lack of knowledge and experience.

Pentothal is supplied in $\frac{1}{2} \mathrm{grm}$. and I grm. ampoules. With the $\frac{1}{2} \mathrm{grm}$. size an ampoule of Io c.c. chemically pure sterile distilled water is supplied and the I grm. size has an.ampoule of 20 c.c. These are put in a bowl of spirit together with the syringes and needles. On the table there is a little bottle of picrotoxin containing 20 c.c. (o.3 per cent. solution) and a box of coramine containing 5 c.c. ampoules in case of accidents. The picrotoxin is used intravenously in various quantities from 2 to 5 c.c. to restore the patient to consciousness and has been used of late with excellent results in severe barbiturate poisoning. Coramine, in case of trouble, should be given in 5 c.coe doses, either intravenously, intramuscularly or subcutaneously. A dose of this size? should only be used in extreme emergency.

By the side of the table with the syringes and the ampoules, there should be an apparatus such as a McKesson, by which nitrous oxide and oxygen can be administered, and a suction apparatus.

These precautions should be applied to all types of anæsthetics, but as some authors are of opinion that intravenous anæsthesia is different, these points are stressed.

A Io c.c. syringe is used because it is easier to manipulate. The anæsthetist equips himself with a dental prop, tongue forceps and an airway, and takes these with the syringe. Swabs and spirit are already with the patient.

For minor operations, i.e., the setting of a wrist or Colles fracture, the patient is asked to lie down on a table in the out-patient department. All tight clothing is eased, and as soon as the surgeon is ready, the upper arm is constricted by the nurse with one hand, and she gently supports the chin with the other. The forearm is prepared with the spirit, and whilst the patient is asked to clench his fist, the anæsthetist rubs the veins towards the shoulder, causing them to stand out. Selecting a suitable vein the needle is inserted with the bevel up into the skin first and then into the vein, thus making a valvular opening. Within fifteen seconds 3 or 4 c.c. is injected and during this time the patient is asked to count and it has been noticed that by the time he manages to reach. twenty he is falling asleep. After a pause of thirty seconds a further 2 or 3 c.c. is given, after which the operation may be begun. If there is still a slight resistance, a further 2 or 3 c.c. is injected, thus making a full total of ro c.c. This dose usually suffices. On waking up during the course of the next few minutes, he is entirely oblivious as to what has happened. He rests for half an hour or so and is then allowed to return home. 
The beginner should give only 3 or 4 c.c. in a period of thirty seconds and repeat the next 3 or 4 c.c. at the same pace. The more advanced student can give the initial dose in fifteen to twenty seconds, but it should not be given more quickly. In outpatients, where the patient is extremely robust, the full ro c.c. can be given in a matter of a minute and only allowing for the original pause of fifteen to thirty seconds after the first 4 c.c. To give an intravenous drug rapidly is courting danger, no matter how experienced the anæsthetist may be or how short the operation.

The disadvantages of a quick injection are that the patient complains of a severe headache, which fortunately is only temporary, double vision and a feeling of dizziness. With regard to the slow method, the patient is likely to recover more slowly, has a slight degree of double vision, but does not complain of a headache or severe degree of dizziness. In other words, the slow method is much more comfortable for the patient than the rapid one.

With every out-patient it is always advisable to see that the stomach is emptied. I have experienced extreme anxiety with some patients who, on being admitted, have said that they have had nothing to eat or drink. Subsequently it has been found after the pentothal has been given that they get complete relaxation of the cardiac sphincter and large quantities of liquid overflow.

For in-patients, the technique is the same for intermittent doses except, as described before, the injection of omnopon grs. I/3rd and scopolamine grs. I/I5oth, which are given one hour previous to the operation. This form of technique is of considerable value as long as the veins are easy to find. In fact it is the common practice to-day for all straightforward operations such as appendicectomy, herniotomy, radical amputation of the breast, thyroidectomy, prostatectomy, etc., to give intermittent injections combined with nitrous oxide and oxygen.

This technique was described by me when using evipan in I934. It was found that by administering nitrous oxide and oxygen the anæsthetic was lengthened for short operations with the maximum amount of comfort for the surgeon, and to assist students who had difficulty in finding a suitable vein in the middle of an operation. If an apparatus like the McKesson is not at hand a gentle feed from an oxygen cylinder to the mouth adds safety. In this type of case, to save disturbing the surgeon, an arm should be left out, supported by the nurse in charge, to enable the anæsthetist to give further injections when necessary. For all short operations such as cystoscopies, sigmoidoscopies, laryngoscopies, bronchoscopies, etc., there is very little need ever to use more than $\frac{1}{2} \mathrm{grm}$, or I grm.

The continuous technique is somewhat different. With the advent of this war, the Jarman-Abel apparatus has been adopted by the various medical services.

With all acute abdomens, chiefly with obstructions where a continuous saline and glucose infusion has been started sometime before the operation, the question of putting another needle into the vein does not arise. It is the practice in such cases to give the patient his usual dose of omnopon and scopolamine, and to inject 4 or 5 c.cs. of pentothal into the tube through which flows the saline and glucose. To ensure the drug getting into the system successfully, the tube is pinched above the site of the needle puncture and held for a minute or two. The patient goes to sleep and is moved to the operating theatre and the anæsthesia is carried on with a nitrous oxide and oxygen machine or an oxygen feed. Small doses of pentothal are given repeatedly into the tube whilst the operation is proceeding, only at the time when further relaxation is required or if the patient is becoming resistant. This is necessary when the surgeon requires to get inside the abdomen, whilst doing a laparotomy, and at the time when he wishes to close the 
abdomen. This type of anæsthetic has been of great success in a large number of cases of obstruction in adults ranging from 18 to 86 and leaves little to be desired, other precautions having been taken.

Pentothal supplemented with nitrous oxide and oxygen is all that is needed for all operations outside the abdomen and generally suffices for an appendicectomy or a colostomy or pelvic operation. It has been my practice (Jarman and Abel, I936) to give pentothal as a means of induction-before giving a spinal-using Etherington Wilson's technique, with a solution of percaine I : I500, and supplemented with nitrous oxide and oxygen, for all major abdominal cases such as gastrectomy, cholecystectomy and abdomino perineal excision of the rectum. The great advantage here is that the patient is entirely unconscious of what kind of anæsthetic has been given-falling asleep in his bed following the intravenous injection. Even in such cases as gastrectomy and cholecystectomy intermittent pentothal has been given, but for the abdomino-perineal operation, it has been found wiser to give a spinal anæsthetic.

\section{EFFECTS.}

During the induction period the following signs have been noticed :-

Heart. All cardiac cases have reacted well with the administration of this drug.

Respirations. These remain steady and gradually become shallow as the drug takes effect. When a full dose has been given the respiratory excursion may become imperceptible. It is at this time that it is wise to give the patient a little oxygen, either by a direct feed or by means of a mask, using a McKesson. To ensure safety, an airway should be inserted as soon as the jaw is relaxed.

Colour. The patient remains a good colour throughout the operation, but if the respirations become so shallow that the oxygen intake is insufficient, then a slight cyanosis may develop.

Pulse. The pulse rate at the commencement of the induction remains steady, gradually increasing. The volume slightly diminishes but returns after a few minutes.

Eyes. The eyes behave in much the same way as under nitrous oxide induction ; that is to say the eyes diverge, the pupils dilate a little and then become central and fixed, the pupil being slightly smaller than normal. Where omnopon and scopolamine have been administered there is no change in the size of the pupil due to the effect of these drugs. The corneal reflex disappears quite early just before the eyes become central after diverging.

Tremors. Tremors develop only when the patient is over stimulated before the drug has had time to take its full effect.

Hiccough. This symptom usually develops in sensitive people, much more so when the drug is given too quickly. It can be got rid of quite easily by giving a little $\mathrm{CO}_{2}$ by the direct method.

Sulphonamides. Where patients have had a course of sulphonamides and especially M \& B 693, no unpleasant symptoms have developed. It has been reported by various members of the medical profession that barbiturates containing the sulphur atom should not be given with these drugs. I have not noticed any of the severe thromboses of the veins which have been complained of, nor has a serious degree of cyanosis been observed, provided small doses of pentothal are given intermittently. Radley Smith (I940) in his paper written in conjunction with Mallinson, who was his anæsthetist, proved on a large number of military casualties that M \& B 693 could be given before, during or 
after the operation, when pentothal had been used, without any unpleasant results. It is firmly believed that thrombosis develops in such cases where the muscular tone of the vein is lacking or has been damaged. Cyanosis is only observed when an overdose has been given.

Recovery. The recovery in most cases is uneventful. The majority of patients wake up as though out of a normal sleep. The striking part is that they all ask when the operation is likely to start, not realising that it has been completed and that they are back in bed. Then in about an hour, they have an intense desire to go to sleep again, which they do for probably an hour or more, and then wake up again as though nothing had happened. There has been no vomiting, neither headaches nor chest complications have been noticed, and restlessness occurs only in a very small percentage of cases.

Dangers. The most obvious danger is an obstructed airway. Therefore a Phillip's or Guedel's airway should be inserted whilst the patient is under the anæsthetic. If this is not done, or removed too soon, the jaw drops and the base of the tongue falls back and causes an obstruction. To counteract this it is well to either insert an airway or open the mouth by means of a gag, apply the tongue forceps to the middle third of the tongue and at the same time push the lower jaw forwards. Stridor is likely to develop if the patient has some mild form of catarrh or an extremely dirty tongue and in all these cases the airway should be watched very carefully. An apparatus to administer oxygen under pressure should be at hand, since by the administration of this gas the symptom is relieved.

Over-dosage. This is a danger which unfortunately occurs far too often. It is not realised sufficiently that only part of the dose should be given and not all of ite To overcome respiratory depression artificial respiration will have to be resorted to a well as the administration of oxygen and carbon dioxide, either by means of a mask $\vec{k}$ or by passing of an intra-tracheal tube. Whilst this is being done, coramine or picrotoxin should be given intravenously or intramuscularly.

Trouble with the veins. In the early days, when pentothal was used in ro per cent. solution, if the vein was missed entirely or the needle went right through it and part of the fluid was injected into the surrounding tissues, it was quite likely that a sore would develop. Now that the 5 per cent. solution is used, this danger is largely overcome, and in America where many anæsthetists use a 2 per cent. solution this condition seldom arises. Therefore it is always wise to make sure that the blood flows back into the syringe and, when injecting, see that the needle is kept steady. If there is the slightest sign of swelling round the site of the puncture the plunger should be withdrawn again to see if the blood flows equally well into the syringe. If this is not so, remove the needle and choose another vein.

There are times when some of the fluid does leak round the vein, and this should be treated at once with a compress of hypertonic saline which should be left on the arm for twenty-four hours. Another method is to treat it with hot fomentations or hot antiphlogistine.

\section{ADVANTAGES AND DISADVANTAGES.}

The advantages of this drug are as follows:-

A. Except for a slight prick in the arm, the patient is unaware of having an anæsthetic.

B. There is no mask over the face.

C. There is no sudden concentration of gas or vapour. 
D. The patient is unconscious of being taken to the theatre, or of any subsequent manipulation by the anæsthetist or the surgeon.

E. On waking the patient does not realise the operation has taken place.

F. He wakes as if out of a natural sleep.

G. There is no sickness, vomiting or even headache.

H. There should be no smell of ether at all in the room, and the patient is usually most grateful for not having his system saturated with such a drug.

The disadvantages are few. (A) Shallow respirations-these have been described and how to overcome them. (B) The fact that the injection is irreversible. This is an anxiety which is relieved by knowing that the drug is broken down quickly in the liver and that as long as the patient is a good colour, and the pulse rate within normal limits, return to consciousness will occur in a short space of time. (c) The possibility of not finding the vein and not having another apparatus to carry on the anæsthetic.

\section{ANTIDOTES.}

Coramine in large doses from 5 to 15 c.c. is the drug of choice in cases of dire necessity. Picrotoxin, another drug which has been used a great deal in cases of severe barbiturate poisoning, has its followers and can be strongly recommended. Intravenously 2 to 3 c.cs. of 0.3 per cent. solution is injected at intervals of fifteen to twenty minutes.

The antidotes do not differ from those of any other form of general anæsthetic. It is hardly worth pointing out that the McKesson or any such other apparatus, with which oxygen can be given under pressure, also carbon dioxide, should be at hand. A large number of people also use the drug alpha-lobeline grs. $3 / 2$ oths or $3 /$ Ioths.

\section{CLINICAL EXPERIENCES.}

Since I930 my experience now goes to well over 15,000 cases. These, of course, include a large number I had when using evipan, and I have realised, since the introduction of pentothal, that the latter is the better drug. All types of cases have been included, from dental cases and minor operations to the various grades of major operations. It has been suggested that a short list of cases should be given where there is no need to use anything else but pentothal. They are as follows :-

Dental cases : Straightforward extractions, preparing and filling of cavities.

Bone operations: Setting of fractures, plasters and removal of sequestra.

Minor gynacological and genito-urinary operations.

Minor operations : Removal of external cysts from any part of the body, empyemata, hæmorrhoids, fistula and fissures, burns and painful dressings.

Pentothal can be used in obstetrics but only in small doses. According to reports received the use of pentothal in obstetrics has been a great success in America, especially for Cæsarean section and manipulation of the fœtus in utero, but my own experience is small.

The technique of intravenous anæesthesia in children is much the same as in adults after the child has reached the age of fourteen years. Below this age the mere fact of the prick of the needle sometimes intimidates the child. This is overcome by suitable premedication such as nembutal grs. $I_{2}^{1}$ up to grs. $2 \frac{1}{2}$ according to the age of the patient, given one hour before the operation. 
With children up to the age of six, it is wiser and kinder to rely on syrup of chloral drm. $\frac{1}{2}$ to drms. 2 or gr. $\frac{1}{2}$ to grs. $I \frac{1}{2}$ nembutal given orally instead of attempting to use the intravenous method. From six to fourteen years, if the child has been properly premedicated, pentothal can be administered without upsetting the patient if skilfully used. It has been noticed that all children get rid of the drug rapidly and on the administration of a second dose they settle down very quickly. It may have a collective effect and in consequence the child needs careful watching until partial consciousness starts to return.

Only in very severe cases have I used continuous pentothal for chidren where a drip saline-glucose infusion has been started some time previous to the operation and in these cases an extraordinarily small amount of pentothal has had to be used. In the majority of cases small doses have been given intermittently followed by nitrous oxide and oxygen.

It is worth while at this point to describe the experience gained with regard to war wounds.

In France pentothal was used in large quantities by itself to enable the medical officer in charge to do what he could in the front line and, during the retreat, he was able to put the patient into an ambulance or lorry whilst in a somnolent state, so as to get him back to the coast with the minimum amount of pain and discomfort.

In cases suffering from bombs or burns, especially the latter, it had been the practice to give grs. $\frac{1}{4}$ to $\frac{1}{2}$ morphia. When admitted to the theatre he was given atropin grs. I/Iooth, anti-tetanic serum having been administered in the wards previously. A small dose of pentothal, say 3 to 5 c.c., was given into a suitable vein, sometimes in the leg, if the arm had been severely burned. As soon as the patient was asleep the clothing, etc., could be removed, the patient cleaned up and, if necessary, a few more c.cs. given whilst the affected area was treated. Shock seemed to be diminished in all these cases. This was strikingly so in all severe wounds caused by bomb splinters or masonry. In more serious wounds an induction of pentothal was given and the anæsthetic was carried on by means of nitrous oxide and oxygen. The blood pressure was taken before and after the operation and whilst recovering in bed. When it started to drop, plasma was given in case of ordinary shock, and this had a most beneficial effect. In other cases where the patient was severely shocked either due to wounds or to hæmorrhage, a saline and glucose drip was started in the ward, which could be changed, according to the reading of the blood pressure or the condition of the patient, to whole blood or plasma.

Chest complications were negligible and the reduction of post-operative shock was particularly remarkable. It was felt that this was entirely due to the barbiturate.

Research work on the possibility of shock being entirely eliminated by the use of pentothal, etc., is now being studied. It is sufficient to add that the general expression by all surgeons is that pentothal has been most beneficial for all cases suffering from severe burns.

\section{RESULTS AND CONCLUSION.}

The results have been most gratifying and out of the large number of cases which have been given barbiturates, there have been no fatalities. The patients are quite willing to have another operation, providing the same type of anæsthetic is used again. There has been na serious case of vomiting and often where there has been slight nausea this has been probably due to the effect of the omnopon and scopolamine and it is quite true to say that the proportion of this type of case is considerably less than with any other anæsthetic. 
In conclusion it is my firm belief that pentothal is the anæsthetic of choice and is an extremely useful addition to the surgical armamentarium provided reasonable precautions are taken. The drug should never be used single-handed, unless conditions specially demand it. It is safer to have someone supporting the jaw whilst the anæsthetic is being administered. The patient's airway should be continuously maintained. Precautions as for any other anæsthetic should always be at hand, namely, an apparatus like the McKesson, Magill's tubes, suction apparatus and all the necessary cardiac and respiratory stimulants.

As long as it is recognised that the induction period is as quick, if not quicker, than the nitrous oxide one, there should be little danger of students being taught how to use it, provided they have a good grounding in dental anæsthetics.

JARMAN, R. \& ABEL, A.L. (1933), Lancet, 2, 18.

REFERENCES.

LUNDY, J. S. \& TOVELL, R. M. (1935), Proc. Staff Meet. Mayo Clinic, 10, 257, 1935.

JARMAN, R. \& ABEL, A. L. (1936), Pentothal Sodium, Intravenous Anæsthesia, Lancet, 1, 42.

QUAYLE, G. (I940), "Continuous Intravenous Anæsthesia for Gynæcological Surgery." Proc. Roy. Soc. 32, 63r.

JARMAN, R. (1936), “ Modern Anæsthesia," Proc. Grad. Med. Jour. 12, 222.

RADLEY SMITH, E. J., (1940), “ A Sulphur Compound in conjunction with Sulphapyridine.”, Brit. Med. Jour., 2, 488. 